\section{Plasma \\ homocysteine and total thiol content in patients with exudative age- related macular degeneration}

K Coral ${ }^{1}$, R Raman ${ }^{2}$, S Rathi ${ }^{3}$, M Rajesh $^{1,4}$,
KN Sulochana ${ }^{1,5}$, N Angayarkanni ${ }^{1}$, PG Paul

K Coral' ${ }^{1}$, R Raman², S Rathi ${ }^{3}$, M Rajesh ${ }^{1,4}$,
KN Sulochana ${ }^{1,5}$, N Angayarkanni ${ }^{1}$, PG Paul and S Ramakrishnan ${ }^{1}$

\begin{abstract}
Purpose Exudative age-related macular degeneration (ARMD) is one of the debilitating ocular complications, which results in permanent blindness. Elevated homocysteine (Hcys) levels have been associated in the development of several vascular diseases. Vascular and oxidative stress theories have been implicated for the development of choroidal neovascularization in exudative ARMD. The aim of the present study was to investigate the possible role of plasma Hcys and thiol content (tSH) as a risk factor for the development of exudative ARMD.
\end{abstract}

Method A total of 16 patients with exudative ARMD and 20 age-matched controls were recruited for the study. Plasma Hcys levels were analysed using Reverse Phase High Performance Liquid Chromatography. Plasma glutathione (GSH) content was determined using $o$-phthalaldehyde (OPA) derivatization and subsequent detection by fluorimeter. Plasma tSH levels were determined by using thiol-specific reagent dithionitrobenzoic acid (DTNB) spectrophotometrically.

Results Plasma Hcys levels in exudative ARMD were elevated three-fold $(18 \pm 5.0 \mu \mathrm{M})$ when compared to healthy controls

$(6.7 \pm 1.8 \mu \mathrm{M})$. There was a two-fold decrease in the GSH and $t S H$ in exudative ARMD when compared with controls. Negative correlation was observed between diminished $\mathrm{tSH}$ and Hcys levels $(r=-0.4837, P=0.05)$. Similarly plasma Hcys levels negatively correlated with GSH content $(r=-0.6620, P<0.05)$. Conclusion Results from our present study revealed that there is an elevated Hcys level and diminished thiol pool content in exudative ARMD that are significant. Eye (2006) 20, 203-207. doi:10.1038/sj.eye.6701853; published online 1 April 2005

Keywords: age-related macular degeneration; homocysteine; glutathione; thiol content; oxidative stress

Introduction

Age-related macular degeneration (ARMD) is one of the leading causes of blindness among the elderly in the world. ${ }^{1}$ It is a complex multifactorial disease that affects the central region of the retina. There are two forms of ARMD, nonexudative (dry) and exudative (wet). Wet ARMD is characterized by the presence of choroidal neovascularization with disciform scar representing the end stage. ${ }^{2}$ Several risk factors such as cigarette smoking, sunlight exposure, obesity, hypertension, and hypercholesterolaemia have been associated with the development of ARMD. ${ }^{3}$ In exudative ARMD the formation of choroidal neovascular membrane (CNV) has been attributed to the elaboration of growth factors, cytokines, and proteases. ${ }^{4}$ Thus different biochemical pathways leading to geographic atrophy and/ or choroidal new vessels may operate simultaneously. Many unanswered questions regarding AMD pathogenesis especially on role of oxidative stress remains. ${ }^{5}$

Epidemiological studies of diet, environmental, and behavioural risk factors suggest that oxidative stress is a contributing factor of AMD. ${ }^{6,7}$ Homocysteine, an
${ }^{1}$ Biochemistry Research Department, Vision Research Foundation Sankara Nethralaya, Chennai, India

${ }^{2}$ Department of Ophthalmology, Vitreoretinal Services, Sankara Nethralaya, Chennai, India

${ }^{3}$ Edgemont High School New York University, NY, USA

${ }^{4}$ National Heart Center \& Johns Hopkins Singapore Vascular Biology Laboratory, Republic of Singapore

${ }^{5}$ Department of Biological Sciences, National University of Singapore, Singapore

Correspondence:

S Ramakrishnan,

Biochemistry Research

Department, Vision

Research Foundation, Sankara Nethralaya, 18 College Road, Chennai 600

006, India

Tel: + 914428271616 Fax: +914428254180

E-mail: drrk@

sankaranethralaya.org

Received: 31 August 2004 Accepted: 24 November 2004

Published online: 1 April 2005 
intermediary amino acid formed during the conversion of methionine to cysteine, is rapidly auto-oxidized in plasma, forming homocystine (Hcys), mixed disulfides, and Hcys thiolactone. Potent reactive oxygen species, including superoxide anion and hydrogen peroxide, are produced during the auto-oxidation of Hcys., 8

Elevated Hcys levels has been shown to induce vascular injury, aiding in atherothrombogenesis and this has been considered as an independent risk factor for the development of vascular diseases. ${ }^{5,6}$ Several lines of evidence suggest that occlusion of choroidal vessels lead to the development of choroidal neovascularization which is a major determinant in promoting visual loss in patients with exudative ARMD. ${ }^{7}$

Axer-Siegel et al $^{10}$ demonstrated an association of elevated plasma level of Hcys and exudative neovascular ARMD in a cohort of 59 patients. In our study, we investigated plasma Hcys, glutathione (GSH) and thiol content $(\mathrm{tSH})$ as the possible risk factor for the development of wet ARMD.

\section{Materials and methods}

\section{Patients and control subjects}

A total of 16 patients with wet ARMD (age group of 51-82 years with the mean age of 66 years ( $11 \mathrm{M}$ and $5 \mathrm{~F}$ ) and 20 age-matched healthy controls in the age group of $55-75$ years with the mean age of 62 years ( $8 \mathrm{M}$ and $12 \mathrm{~F}$ ) were recruited for the study. Demographic details are presented in Table 1. Patients recruited for the study either had $\mathrm{CNV}$ or disciform scar. The grading of the $\mathrm{CNV}$ was based on the age-related eye disease study group (AREDS) recommendation. Subjects with history of diabetes mellitus, renal disease, hypertension,

Table 1 Demographic details of patients and control subjects

\begin{tabular}{rcl}
\hline S. No & Age/sex & Clinical diagnosis \\
\hline 1 & $58 / \mathrm{F}$ & CNVM occult-OD, Dry ARMD_OS \\
2 & $61 / \mathrm{F}$ & Blind eye-OD, Disciform scar-OS \\
3 & $67 / \mathrm{F}$ & Dry ARMD_OD, CNVM occult-OS \\
4 & $81 / \mathrm{F}$ & CNVM classic-OD, Dry ARMD-OS \\
5 & $72 / \mathrm{M}$ & Disciform scar-OD, Disciform scar-OS \\
6 & $51 / \mathrm{M}$ & CNVM occult-OD, Dry ARMD-OS \\
7 & $62 / \mathrm{M}$ & CNVM occult-OD, Dry ARMD-OS \\
8 & $72 / \mathrm{F}$ & Disciform scar-OD, Disciform scar-OS \\
9 & $62 / \mathrm{M}$ & CNVM occult-OD, Dry ARMD-OS \\
10 & $65 / \mathrm{M}$ & Dry ARMD-OD, Disciform scar-OS \\
11 & $69 / \mathrm{M}$ & Dry ARMD-OD, Disciform scar-OS \\
12 & $60 / \mathrm{M}$ & CNVM classic-OD, Dry ARMD-OS \\
13 & $62 / \mathrm{M}$ & Normal-OD, Classic CNVM-OS \\
14 & $81 / \mathrm{M}$ & CNVM occult-OD, Dry ARMD-OS \\
15 & $82 / \mathrm{M}$ & Dry ARMD-OD, CNVM occult-OS \\
16 & $58 / \mathrm{M}$ & Dry ARMD-OD, CNVM occult-OS \\
\hline
\end{tabular}

cardiovascular disease, smokers, alcoholics, and subjects who are on antioxidant supplements were excluded from the study. The physician and ophthalmologist ruled out any systemic/ophthalmic diseases from the control subjects before recruitment after a detailed check up. Informed consent was obtained from all the participants in the study. The authors' institutional research and ethical committee approved the study. All procedures pertaining to human subjects strictly adhered to tenets of Helsinki declaration.

Blood samples were collected after ensuring overnight fasting and plasma was separated immediately. All the assays were performed on the same day.

\section{Chemicals}

All the fine chemicals used in the study were procured from Sigma chemical company (MO, USA) unless specified. HPLC solvents were purchased from E-Merck Chemicals, Mumbai, India.

\section{Determination of plasma homocysteine}

Plasma Hcys levels were determined using HPLC as described by Jayatilleke and Shaw with slight modifications. ${ }^{11}$ In brief, equal volume of $10 \%$ TCA (W/V) was added to $0.5 \mathrm{ml}$ plasma and vortexed thoroughly followed by centrifugation at $5000 \mathrm{rpm}$ for $15 \mathrm{~min}$ at $4^{\circ} \mathrm{C}$. The supernatant was filtered through $0.22 \mu$ syringe filter. In all, $10 \mu \mathrm{l}$ aliquot of the filtered supernatant was diluted to $1.0 \mathrm{ml}$ with degassed Milli Q water. From this $50 \mu \mathrm{l}$ was injected into C18 column (Licrosphere, Merck,

Darmstadt, Germany). Isocratic elution was performed using $0.0025 \mathrm{M} \mathrm{Na}_{2} \mathrm{HPO}_{4}$ buffer, $\mathrm{pH} 3.5$ containing $50 \mu \mathrm{M}$ tetrabutylammonium dihydrogen phosphate and $13 \%$ methanol, at the flow rate of $0.3 \mathrm{ml} / \mathrm{min}$. Elution was monitored at $190 \mathrm{~nm}$. The analysis was carried out using Agilent 1100 series HPLC system equipped with binary solvent pump, column thermostat, and variable wavelength detector. Prior to analysis of Hcys in clinical samples, the system was calibrated with authentic Hcys standards in the range of $3.0-50.0 \mu \mathrm{M}$. Intra-assay variation for Hcys was found to be $1.35 \mu \mathrm{M}$.

\section{Determination of plasma GSH}

Plasma GSH was determined by following the method of Miuo-Lin Hu with slight modifications. ${ }^{12}$ Briefly $0.5 \mathrm{ml}$ of plasma was added to $0.5 \mathrm{ml}$ of ice cold $10 \%$ TCA, vortexed and kept in ice for $10 \mathrm{~min}$ followed by centrifugation to remove the protein pellet. To $0.2 \mathrm{ml}$ aliquot of the supernatant added $1.7 \mathrm{ml}$ of $0.1 \mathrm{M}$ sodium phosphate buffer containing $5 \mathrm{mM}$ EDTA, $\mathrm{pH} 8.0$ and $0.1 \mathrm{ml}$ of $o$-phthalaldehyde $(1 \mathrm{mg} / \mathrm{ml}$ in methanol). The 
mixture was incubated at room temperature for $15 \mathrm{~min}$ and the fluorescent, $o$-phthalaldehyde derivative of GSH in plasma was determined in flourimeter (Perkin Elmer LS30, USA) by measuring the excitation at $350 \mathrm{~nm}$ and emission at $420 \mathrm{~nm}$. Prior to estimation of GSH in clinical samples the system was calibrated with authentic standards in the range of $0.3-8 \mu \mathrm{M}$ GSH. Intra-assay variation was found to be $0.45 \mu \mathrm{M}$.

\section{Determination of plasma total $\mathrm{tSH}$}

Plasma total $\mathrm{tSH}$ was determined by the method of Miuo-Lin Hu with slight modifications. ${ }^{12}$ Briefly $50 \mu \mathrm{l}$ of plasma was mixed with $0.25 \mathrm{M}$ Tris EDTA buffer, $\mathrm{pH} 8.2$ and the absorbance was measured at $412 \mathrm{~nm}$. To this $20 \mu \mathrm{l}$ of $10 \mathrm{mM}$ dithionitrobenzene (DTNB) was added and kept at room temperature for $15 \mathrm{~min}$. The absorbance was again measured at $412 \mathrm{~nm}$ against DTNB blank. The total $\mathrm{tSH}$ was calculated using the molar absorption coefficient (E) $13600 \mathrm{~cm}^{-1} \mathrm{M}^{-1}$. Intra-assay variation was found to be $0.07 \mathrm{mM}$.

\section{Statistical analysis}

All values were expressed as mean \pm SD. Statistical tests such as Student's ' $t$ ' and Pearson $\chi^{2}$ test were used to compare means and proportions, respectively. Pearson's correlation test was employed to assess the relationship between Hcys levels with GSH, and tSH. Statistical significance was defined as $P<0.05$.

\section{Results}

The levels of plasma Hcys, GSH, and $\mathrm{tSH}$ determined in patients and control subjects are given in Table 2. There was a statistically significant difference in plasma Hcys between the cases and controls. $(P \leqslant 0.05)$. Plasma Hcys levels were found to be three-fold higher in patients with wet ARMD compared to control subjects (95\% CI for mean difference $-14.26 \leftrightarrow-9.12$ ), while the plasma GSH levels and the $\mathrm{tSH}$ levels were decreased significantly by nearly $50 \%(P \leqslant 0.05,95 \% \mathrm{CI}$ for mean difference: GSH levels $1.607 \leftrightarrow 3.31$ and for $\mathrm{tSH}$ levels $0.11 \leftrightarrow 0.27$ ).

The gender differences in levels between the cases and controls were not statistically significant (Pearson's $\left.\chi^{2}=-2.953, P=0.87\right)$

A significant correlation was observed between levels of Hcys and GSH content in patients with wet ARMD $(r=-0.6620, P<0.05)$ (Figure 1$)$. Similarly a significant negative correlation was observed between $\mathrm{tSH}$ content and Hcys levels $(r=-0.4837, P=0.05)$ in patients with wet ARMD (Figure 2).

\section{Discussion}

Choroidal neovascularization has been attributed to be the major cause of visual loss in patients with wet ARMD. ${ }^{13}$ Pathogenesis of choroidal neovascularization in ARMD involves a complex interplay of environmental, biochemical changes, and genetic predisposition. ${ }^{14}$

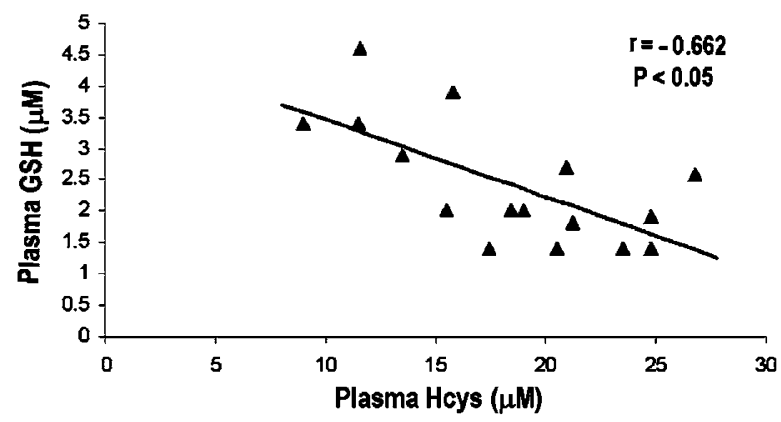

Figure 1 Correlation analysis between plasma Homocysteine GSH.

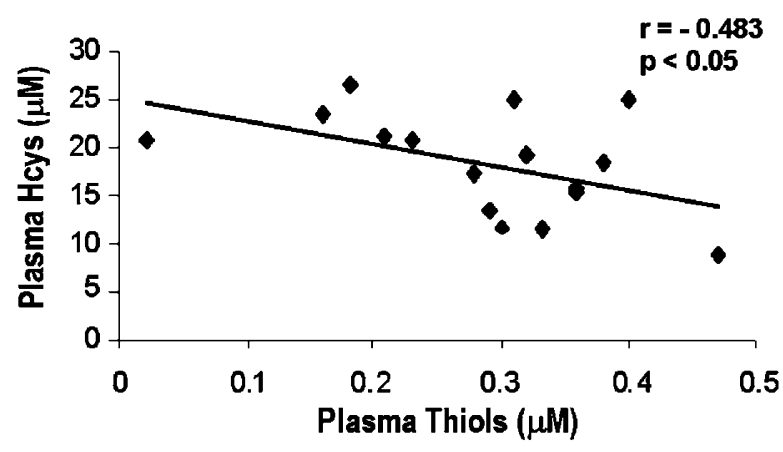

Figure 2 Correlation analysis between plasma Homocysteine and thiol.

Table 2 Demographic details of patients and control subjects

\begin{tabular}{|c|c|c|c|c|c|c|c|c|}
\hline \multirow[t]{2}{*}{ Biochemical parameters } & \multicolumn{2}{|c|}{ Cases $(\mathrm{n}=16)$} & \multicolumn{2}{|c|}{ Controls $(\mathrm{n}=20)$} & \multicolumn{4}{|c|}{ Statistical data } \\
\hline & Mean & $S D$ & Mean & $S D$ & P-value & $95 \%$ CI for mean & Difference & Power \\
\hline $\mathrm{GSH}(\mu \mathrm{M})$ & 2.43 & 0.98 & 4.89 & 1.43 & $<0.0001$ & 1.607 & 3.31 & 1 \\
\hline Homocysteine $(\mu \mathrm{M})$ & 18.39 & 5.29 & 6.70 & 1.81 & $<0.0001$ & -14.26 & -9.12 & 99.74 \\
\hline Thiol content (mM) & 0.29 & 0.11 & 0.48 & 0.12 & $<0.0001$ & 0.11 & 0.27 & 99.9 \\
\hline
\end{tabular}


Several investigators have favoured oxidative stress in ARMD. ${ }^{15-18}$ Hahn et $a l^{19}$ has reported increased accumulation of iron in the retinal pigment epithelium and Bruch's membrane of patients with ARMD. The significantly higher concentration of lipid peroxidation products in patients with ARMD indicates an important pathogenic role of oxidoreduction disturbance. Such a disturbance could cause undesirable oxidation of proteins, lipids and lipoproteins especially of biomembranes.

Hcys has been shown to undergo autoxidation in the presence of transition metal ions like iron which culminates in the generation of hydroxyl radical $\left(\mathrm{OH}^{\bullet}\right)$. $\mathrm{OH}^{\bullet}$ thus generated initiates the oxidation of LDL and this has been shown to induce the vascular dysfunction. ${ }^{20-22}$

In our present study, we have detected elevated levels of Hcys and diminished $\mathrm{tSH}$ in patients with wet ARMD. A recent study on the assessment of the relationship between plasma Hcys levels and exudative neovascular AMD has suggested that there is an association between an elevated plasma level of Hcys and exudative neovascular ARMD but not dry ARMD. ${ }^{10}$ An earlier study by Heuberger et $a l^{23}$ has shown that ARMD does not appear to be associated with Hcys or its dietary determinants and has suggested further investigations in subgroups with low folate status. ${ }^{23}$ Thus, further studies have to be performed to assess the role of nutritional status in correlation between hyperhomocystenaemia and wet ARMD.

Under normal circumstances, spontaneous oxidation of Hcys is prevented by GSH. However, during pathological conditions and in ageing process GSH and thiol pool has been reported to decrease, which aids in Hcys oxidation that results in oxidative insult to the tissue. ${ }^{24,25}$ Recently, Sameic et al ${ }^{26}$ has reported that GSH levels were diminished in plasma of patients with ARMD and ageing. In one of the study reports, while estimating the enzymatic and nonenzymatic components of the antioxidant system it was shown that the average concentrations of vitamin $\mathrm{A}$ and $\mathrm{C}$ were low and vitamin $\mathrm{E}$ and GSH were significantly higher in patients with ARMD than in the control group, with the activity of almost all the antioxidant enzymes being high, showing that there is an adaptive increase in the antioxidant barrier of mostly the enzymatic components. ${ }^{27}$ The multicentre, double-blind cross-sectional study reported by Everklioglu et al has shown that late ARMD patients had significantly lower antioxidant enzyme levels and higher MDA levels when compared with early ARMD patients, which may reflect the levels of the various antioxidants including GSH. ${ }^{16}$ Therefore, grouping of the patients based on the clinical picture seems to be crucial before arriving at conclusions.
Based on the results from our present study and supportive theories by other investigators, it is quite possible that hyperhomocysteinaemia (Hhcys) and prevailing oxidative stress could synergistically play an important role in the pathogenesis of wet ARMD by inducing vascular dysfunction.

\section{References}

1 Evans JR. Risk factors for age related macular degeneration. Prog Ret Eye Res 2001; 20: 227-253.

2 Fine SL, Berger JW, Maguire MG, Ho AC. Age related macular degeneration. $N$ Eng J Med 2000; 342: 483-492.

3 Anand R, Bressler SB, Davis MD, Ferris FL, Klein R, Cindblad AS et al. Age related eye disease study research group: risk factors associated with age related macular degeneration. A case control study in the age related eye disease study: age related eye disease study report number 3. Ophthalmology 2000; 107: 2224-2232.

4 Compochiaro PA, Soloway P, Ryan SJ, Miller JW. The pathogenesis of choroidal neovascularization in patients with age related macular degeneration. Mol Vis 1999; 5: 34-38.

5 Zarbin MA. Current concepts in the pathogenesis of agerelated macular degeneration. Arch Ophthalmol 2004; 122(4): 598-614.

6 Ambai J, Ambati BK, Yoo SH, Jancholev S, Adamis AP. Age related macular degeneration: etiology, pathogenesis and therapeutic strategies. Surv Ophthalmol 2003; 48: 257-293.

7 Totan Y, Cekic O, Borazan M, Uz E, Sogut S, Akyol O. Plasma malondialdehyde and nitric oxide levels in age related macular degeneration. Br J Ophthalmol 2001; 85(12): 1426-1428.

8 Harker LA, Ross R, Slichter SJ, Scott CR. Homocystineinduced arteriosclerosis: the role of endothelial cell injury and platelet response in its genesis. J Clin Invest 1976; 58: 731-741.

9 Ian F, McDowell W, Derek L. Homocysteine and endothelial dysfunction: a link with cardiovascular disease. J Nutr 2000; 30: 369S-372S.

10 Axer-Siegel R, Bourla D, Ehrlich R, Dotan G, Benjamini Y, Gavendo $\mathrm{S}$ et al. Association of neovascular age-related macular degeneration and hyperhomocysteinemia. Am J Ophthalmol 2004; 137(1): 84-89.

11 Jayatilleke E, Shaw S. A high performance liquid chromatographic assay for reduced and oxidized glutathione in biological samples. Ann Biochem 1993; 214: 452-457.

12 Miuo-Lin Ho. Measurement of protein thiol groups and glutathione in plasma. Methods Enzymol 1994; 233: 381-385.

13 Bressler EM, Bressler SB, Fine LS. Age related macular degeneration. Surv Ophthalmol 1988; 32: 375-413.

14 Young RW. Pathophysiology of age related macular degeneration. Surv Ophthalmol 1987; 31: 291-306.

15 Winkler BS, Boultan ME, Gottch JD, Strenberg P. Oxidative damage and age-related macular degeneration. Mol Vis 1995; 5: 32-42.

16 Yildirim O, Ates NA, Tamer L, Muslu N, Ercan B, Atik U et al. Changes in antioxidant enzyme activity and malondialdehyde level in patients with age-related macular degeneration. Ophthalmologica 2004; 218(3): 202-206. 
17 Evereklioglu C, Er H, Doganay S, Cekmen M, Turkoz Y, Otlu B et al. Nitric oxide and lipid peroxidation are increased and associated with decreased antioxidant enzyme activities in patients with age-related macular degeneration. Doc Ophthalmol 2003; 106(2): 129-136.

18 Beatty S, Koh H, Phil M, Henson D, Boulton M. The role of oxidative stress in the pathogenesis of age-related macular degeneration. Surv Ophthalmol 2000; 45(2): 115-134.

19 Hahn P, Milam AH, Donaief JL. Maculas affected by agerelated macular degeneration certain increased chelatable iron and Bruch's membrane. Arch Opthalmol 2003; 121: 1099-1105.

20 Hofmann MA, Lalla E, Lu Y, Gleason MR, Wolf BM, Tanji $\mathrm{N}$ et al. Hyperhomocysteinemia enhances vascular inflammation and accelerates atheroselerosis in a murine model. J Clin Invest 2001; 107: 675-683.

21 Starke BG, Harlan JM. Endothelial cell injury due to copper catalyzed hydrogen peroxide generation from homocysteine. J Clin Invest 1986; 77: 1370-1376.

22 Harpel PC, Chang VT, Burth W. Homocysteine and other sulphydryl compounds enhance the binding of lipoprotein (a) to fibrin a potential biochemical link between thrombosis, atherogenesis and sulphydryl compound metabolism. Peox Natl Accel Sci USA 1992; 89: 10193-10197.

23 Heuberger RA, Fisher AI, Jacques PF, Klein R, Klein BE, Palta $\mathrm{M}$ et al. Relation of blood homocysteine and its nutritional determinants to age-related maculopathy in the third National Health and Nutrition Examination Survey. Am J Clin Nutr 2002; 76(4): 897-902.

24 Zappacosta B, Mordente A, Persichilli S, Minucci A, Carlino P, Martorana GE et al. Is homocysteine a pro-oxidant?. Free Radic Res 2001; 35: 499-505.

25 Jones DP, Kurtz JC, Sternberg P. Thiol and disulfide forms of glutathione, cysteine, cysteinylglycine and homocysteine in human plasma. FASEB J 1997; 11: A150.

26 Samiec PS, Botsch CD, Flagg EW, Kurtz JC, Sternberg Jr P, Reed RL et al. Glutathione in human plasma: decline in association with aging, ARMD and diabetes. FRBM 1998; 24: 699-704.

27 Nowak M, Swietochowska E, Wielkoszynski T, Marek B, Karpe J, Gorski J et al. Changes in blood antioxidants and several lipid peroxidation products in women with agerelated macular degeneration. Eur J Ophthalmol 2003; 13(3): 281-286. 